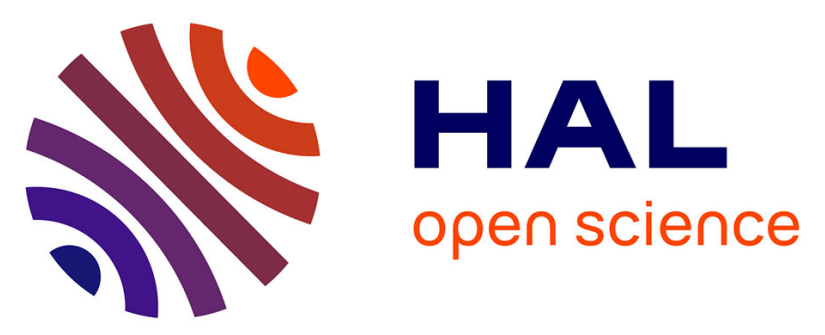

\title{
Texture and Porosity Effects on the Thermal Radiative Behavior of Alumina Ceramics
}

Olivier Rozenbaum, Domingos de Sousa Meneses, Patrick Echegut

\section{To cite this version:}

Olivier Rozenbaum, Domingos de Sousa Meneses, Patrick Echegut. Texture and Porosity Effects on the Thermal Radiative Behavior of Alumina Ceramics. International Journal of Thermophysics, 2009, 30 (2), pp.580-590. 10.1007/s10765-008-0510-1 . insu-00338246

\section{HAL Id: insu-00338246 \\ https://hal-insu.archives-ouvertes.fr/insu-00338246}

Submitted on 13 Nov 2008

HAL is a multi-disciplinary open access archive for the deposit and dissemination of scientific research documents, whether they are published or not. The documents may come from teaching and research institutions in France or abroad, or from public or private research centers.
L'archive ouverte pluridisciplinaire HAL, est destinée au dépôt et à la diffusion de documents scientifiques de niveau recherche, publiés ou non, émanant des établissements d'enseignement et de recherche français ou étrangers, des laboratoires publics ou privés. 


\title{
Texture and porosity effects on the thermal radiative behavior of alumina ceramics.
}

\author{
O. Rozenbaum ${ }^{1 *}$, D. De Sousa Meneses ${ }^{2}$, P. Echegut ${ }^{2}$
}

\section{Olivier ROZENBAUM ${ }^{1 *}$}

Assistant professor,

Université d'Orléans, CNRS/INSU, Université de Tours

Institut des Sciences de la Terre d'Orléans (ISTO), UMR 6113

1A, rue de la Férollerie, 45071 Orléans Cedex 2, France

rozenbaum@cnrs-orleans.fr

Phone: 332-38-25-52-44

Fax: 332-38-63-64-88

\section{Domingos DE SOUSA MENESES ${ }^{2}$}

Assistant professor,

Conditions Extrêmes et Matériaux : Haute Température et Irradiation (CEMTHI), UPR 3079

1D avenue de la Recherche Scientifique, 45071 Orléans Cedex 2, France

desousa@cnrs-orleans.fr

Phone: 332-38-25-55-34

Fax: 332-38-63-81-03

\section{Patrick ECHEGUT ${ }^{2+}$}

Director of research,

Conditions Extrêmes et Matériaux : Haute Température et Irradiation (CEMTHI), UPR 3079

1D avenue de la Recherche Scientifique, 45071 Orléans Cedex 2, France

echegut@cnrs-orleans.fr

Phone: 332-38-25-55-19

Fax: 332-38-63-81-03

\footnotetext{
* This study was performed at CEMTHI laboratory.
} 


\begin{abstract}
Thermal and optical properties of ceramics are dependent on radiation scattering and cannot be determined by the only knowledge of their chemical composition as for single crystals. In this paper, we investigate extrinsic effects such as roughness, porosity and texture on spectral emissivity of alumina ceramics. Roughness effects have an influence mainly in the opaque zone; an important porosity dependence and the presence of a critical porosity threshold were also pointed out in the semi-transparent zone. Furthermore, it was shown that two ceramics with similar total porosity but with different textures possess radically different emissivities, showing that grain size, pore size and spatial repartition of the grains is also crucial for the comprehension of the ceramics thermal properties.
\end{abstract}

Keywords: ceramics, texture, emissivity spectra, infrared spectroscopy, high temperature. 


\section{1-Introduction}

A precise characterization of the thermal radiation heat transfer efficiency of structural materials is mandatory to design and optimize devices working at high temperature such as glass making furnaces or thermal shields. To determine these properties, a direct measurement of the spectral emissivity is a must as shown in the available literature on this subject (e.g. [12]). The optical and radiative properties of single crystals and non porous materials are relatively well-known and completely defined by the only knowledge of intrinsic parameters such as the complex refractive index and the thickness of the material [3-5]. Nevertheless, these properties are modified by extrinsic parameters in the case of porous materials such as ceramics. Some authors [6-12] pointed out the effect of the structure of ceramics, the roughness, the porosity, the grain and pore size, the birefringence and the role of impurities within the grain boundaries. However, as shown by Grimm et al. [8], Budworth [13] and Peelen [6], the effect of the birefringence is negligible compared to the pore size effect. Also, the only knowledge of the chemical formula of a material is not sufficient to have a perfect understanding of the associated ceramics emissivity.

In this paper, it is shown how some extrinsic contributions act on the spectral emissivity of alumina ceramics. All the reported measurements were performed with a set-up [2] that enables to obtain accurate emissivity spectra of semitransparent porous and non porous materials. After a brief description of the set-up and the studied ceramics, the influences of the porosity, the texture effect on the radiative properties of alumina ceramics will be exposed and discussed.

\section{Material and method}

\subsection{Spectral emissivity measurement}

The apparatus, previously described in details [2], consists in a FTIR Bruker IFS 113v spectrometer which was enhanced with an external optical device that allows the measurement of infrared fluxes emitted by a sample and a black body furnace for identical geometrical conditions. To achieve very high temperatures (2500 K) and avoid parasite flux due to hot closure confinement, a $\mathrm{CO}_{2}$ laser heating was chosen. The particular design of the heating configuration enables to obtain a quasi homogeneous temperature on the measured 
sample area. The sample temperature was determined at a particular wavelength called the “Christiansen point” [1-2]. Indeed, at this wavelength polar dielectric materials such as oxide materials behave like a blackbody $(\varepsilon=1)$. This characteristic point suffers little change with temperature and was quasi independent on the texture and the material roughness. Hence, the temperature determination can then be obtained by using the spectrometer as a pyrometer at the Christiansen wavenumber. For alumina materials, the Christiansen wavelength is near $1030 \mathrm{~cm}^{-1}$.

For stability reasons and better precision, the temperature of the blackbody furnace was maintained at $1673 \mathrm{~K}$. So, the spectral emissivity of a sample at temperature $\mathrm{T}$ was calculated by the following expression [14]:

$\varepsilon(\mathrm{T})=\frac{\mathrm{FT}\left(\mathrm{I}_{\mathrm{S}}^{\mathrm{mes}}-\mathrm{I}_{\mathrm{RT}}^{\mathrm{mes}}\right)}{\mathrm{FT}\left(\mathrm{I}_{\mathrm{BB}}^{\mathrm{mes}}-\mathrm{I}_{\mathrm{RT}}^{\mathrm{mes}}\right)} \times \frac{\mathrm{P}_{\mathrm{BB}}-\mathrm{P}_{\mathrm{RT}}}{\mathrm{P}_{\mathrm{S}}-\mathrm{P}_{\mathrm{RT}}}$

where FT was the Fourier transform, $I_{S}^{\text {mes }}, I_{B B}^{\text {mes }}, I_{R T}^{\text {mes }}$ were the interferograms recorded respectively for the sample, the blackbody reference and the room temperature parasite flux, $\mathrm{P}_{\mathrm{S}}, \mathrm{P}_{\mathrm{BB}}$ and $\mathrm{P}_{\mathrm{RT}}$ were the calculated Planck's function at the sample temperature, the blackbody furnace, and a blackbody at room temperature.

\subsection{Materials}

The choice of several alumina ceramics with perfectly controlled characteristics was imposed by several constraints. The first one was the necessity to obtain enough emitted energy in the mid infrared range or, in other words, the necessity to select a material whose texture does not evolve with temperature, allowing high temperature measurements. Another one was the fact that the samples must be good absorbers at the $\mathrm{CO}_{2}$ laser frequency to be efficiency heated.

Two sets of high purity alumina ceramics covering a large range of porosity and with a fixed texture were obtained from an industrial supplier (Desmarquest) and from a French public laboratory (CEA-CEREM). Hereafter the samples were labeled by the following nomenclature: Compound(Origin)-Porosity. So, a CEA's alumina ceramic with a porosity of $\mathrm{X}$ \% will be named $\mathrm{Al}(\mathrm{C})-\mathrm{X}$. For the ceramics made by Desmarquest, the letter $\mathrm{D}$ was used for the classical process of fabrication and D' for one particular ceramic. Indeed, most of the 
alumina ceramics elaborated by Desmarquest resulted from a classical industrial process from a biomedical powder (alumina $\alpha$, purity $99.9 \%$ ). All these ceramics were made from powders with the same grain diameter (approximately $0.5 \mu \mathrm{m}$ ) and different porosities were obtained by using different sintering temperatures (Tableau 1). Except for one particular ceramic noted $\mathrm{Al}\left(\mathrm{D}^{\prime}\right)-23.2$ that was made from a bimodal grain distribution in order to study the effect of the texture. The second set of ceramics came from the CEA-CEREM laboratory and was made from an $\alpha$ alumina powder with purity higher than $99.99 \%$. The powder was calcined at 1273 $\mathrm{K}$, to obtained larger grains and then crushed. The resulting clusters was then sieved at 400 $\mu \mathrm{m}$ and pressed at 1500 bars with an isostatic press to form alumina rods. Finally, the different porosities were obtained by using different sintering temperatures (Tableau 1). As the only varying parameter during the elaboration process was the sintering temperature, the resulting ceramics possessed analogous texture and differ only by their porosity. Indeed, the observation of different ceramics fractures by Scanning Electron Microscopy (SEM) was carried out to control the sintering effect and to obtain the average grain size and morphology (Figure 1, Figure 2, Figure 3, and table 1). For porosities (measured by geometrical measurements and helium pycnometry) lying between 3.8 and 29.2 \% (CEA's samples), all the ceramics exhibits analogous morphology and spatial arrangement. The only significant change was the mean grain size that slightly increases along with the higher sintering temperatures. Furthermore, image analysis on Desmarquest ceramics (Al(D)-0.6 and Al(D)3.5) showed that these materials have roughly similar grain size and spatial repartition. These sets of samples were then appropriate to study the influence of the porosity on the spectral emissivity.

In contrast, the bimodal grain distribution of the $\mathrm{Al}\left(\mathrm{D}^{\prime}\right)-23.2$ sample belonged to the $5-50 \mu \mathrm{m}$ range. Mercury intrusion porosimetry analysis showed that the mean pore size of this sample was 40 times as high as the mean pore size of the other ceramics (not shown here). The large pore size was explained by the presence of large grains $(50 \mu \mathrm{m})$ that originates macropores.

\section{Results}

For the study of the porosity effect all the emissivity spectra were acquired on one millimeter thick polished samples at $1350 \mathrm{~K}$ in order to stay below the sintering temperature and retain the initial texture of the most porous ceramic. To ensure that the spectra obtained on a single sample were self-averaged, several measurements on different samples with identical texture 
and equivalent porosity (table 1) were performed. For the sake of clarity, only sets of the more representative samples were kept in the following figures.

In the 400-1300 $\mathrm{cm}^{-1}$ range (Figure 4), alumina ceramics were opaque (phonon zone) and the optical properties were only due to the material surface. For higher wavelengths, i.e. between 1300 and $2500 \mathrm{~cm}^{-1}$, the absorption coefficient decreases and the material becomes semitransparent. For the most porous samples, broad bands appeared in the emissivity spectra between 2600 and $4000 \mathrm{~cm}^{-1}$ (Figure 4) and were not the only consequence of the porosity. The microscopic origin of these bands comes from the hydroxyls groups and trapped water molecules. These bands did not appear in dense ceramics because of their closed porosity and the fact that during their elaboration they were sintered at higher temperatures by comparison with the most porous ones. Without these contributions, i.e. above $4000 \mathrm{~cm}^{-1}$, the absorption coefficient becomes intrinsically sufficiently weak to consider the material as transparent and the emissivity negligible [5].

The porosity effect was observed by the juxtaposition of the spectral emissivities of the CEA's samples ( $\mathrm{Al}(\mathrm{C})-3.8$ to $\mathrm{Al}(\mathrm{C})-29.2)$ and the Demarquest's samples (Figure 4). A rapid overview on this figure showed two different aspects of the porosity effect: a frequency shift of the transmissivity edge by comparing it to those of the single crystal, and an enhancement of the emissivity in the phonon wavenumber range (opaque zone).

\subsection{Roughness effect in the opaque zone}

The porosity dependence on the spectral emissivity in the phonon range was reported in Figure 5. With the porosity increase, a strengthening of the surface scattering was noticed which results in a progressive weakening of the reflection bands, and then an enhancement of the emissivity. Besides, in addition to these progressive modifications, the band shapes were markedly modified in comparison with those of the single crystal but the bands shapes did not evolve significantly with the increase in porosity between 500 and $900 \mathrm{~cm}^{-1}$. Several authors [10, 15-19] showed that the band shape of the spectral emissivity was dependent on the grain size and the grain shape constituting the surface of the sample. Several types of behaviors appeared according to the particle size and the value of the absorption coefficient $\mathrm{K}$ (e.g. [16]). For high values of absorption coefficient (opaque zone), these authors showed that the particle size decrease induced a reflectivity drop fall leading to an increase of emissivity. 
Furthermore, Anderson and Ribbing [20] have pointed out that the spectral emissivity was also particle shape dependent. Following their work, a distortion of the reflection band, near the longitudinal optic mode wavenumber $\left(850 \mathrm{~cm}^{-1}\right.$ for alumina), was due to surface defects with spherical shape. This general trend was in accordance with the bump localized in the emissive spectra, around $720 \mathrm{~cm}^{-1}$ (Figure 5). Indeed, SEM images obtained on the ceramics of CEA show that the grains were polyhedrons with quasi spherical shape (Figure 2).

\subsection{Porosity effect}

The porosity dependence on the spectral emissivity in the semitransparent region was reported in Figure 6 and the emissivity evolution with respect to the porosity was visualized for three wavenumbers in Figure 7. In this spectral range, ceramics emissivities were always higher than those of the single crystal. Furthermore, for small values of total porosity (0-5 \% range) the emissivity increased as the ceramics became more and more porous. To our knowledge, few results related to this subject were published [6-8, 11-12, 21-23]. Some authors [19, 24] determined by transmissivity measurements that, in the semitransparent region, the radiation scattering inside ceramics was mainly due to the pores. Scattering by grain interfaces in weak anisotropic material such as dielectric oxides in the semitransparent zone was always weak in comparison with the previous mode. With transmissivity measurements made on dense ceramics ( $<2 \%$ of porosity) Grimm [8] showed that a density decrease i.e. a porosity increase, strengthens radiation scattering (backscattering) and lowers the sample transmissivity (inducing an emissivity increase). These results were consistent with the present work and explain the observed phenomenon. Besides, for higher total porosity, a change of behavior was observed since the emissivity decreases continuously (Figure 7). This result shows the existence of a critical porosity for which the emissivity reaches the highest value in the semitransparent zone for this type of texture.

\subsection{Texture influence}

As for porosity, spatial repartition, grain size and pores size, parameters that we call texture, influence largely the radiative properties of a material. This point can be brought to the fore by a comparison between the $\mathrm{Al}\left(\mathrm{D}^{\prime}\right)-23.2$ and the $\mathrm{Al}(\mathrm{C})-20.6$ samples that possess similar total porosity but very different textures as showed in Figure 2 and Figure 3. The main modifications between the spectral emissivity spectra of these two samples (Figure 8) occur in 
the semitransparent zone. Unlike the other previously studied ceramics, the $\mathrm{Al}\left(\mathrm{D}^{\prime}\right)-23.2$ ceramic have a much lower emissivity than the single crystal between 1300 and $1800 \mathrm{~cm}^{-1}$ and the spectral emissivity of this sample was radically different from the $\mathrm{Al}(\mathrm{C})-20.6$ emissivity spectra. For higher wavelengths, the emissivity increases to become higher than those of the single crystal and tends to those of the $\mathrm{Al}(\mathrm{C})-20.6$ sample in the transparent zone. The only total porosity knowledge is then not sufficient to predict the radiative behavior of porous materials and confirmed the importance of the texture information.

\section{Discussion}

What is the phenomenon that could explain the critical threshold showed on Figure 7 ? For the lowest porosities, pores induces thermal radiation scattering that lengthens the mean travel of the radiation and then increase the apparent optical thickness of the media. Also, the radiation path inside the ceramic was longer in comparison with those performed in the single crystal of same thickness. Hence, as the absorption is strengthened, the emissivity of the ceramic is greater than those of the single crystal. Furthermore, as the materials become more and more porous, scattering was more and more important and the emissivity increase, up to a critical porosity threshold. However, above this threshold, scattering was so important that backscattering becomes more efficient and induced progressively a decrease of the apparent optical thickness of the ceramic. Then, the radiation was less absorbed and the emissivity was lowered.

This behavior for porosities lower than the critical threshold was encountered for samples where the backscattered part of the radiation was weak in comparison with the transmitted part, or in other words, for samples having a diffuse transmissivity higher than the diffuse reflectivity [5]. The opposite behavior was observed for porosity higher than the critical threshold, i.e. for samples having a diffuse reflectivity higher than the diffuse transmissivity. The critical threshold represented the limit between a reflective (porosity $>5 \%$ ) and a transmissive behavior. All these explanations are in agreement with the results of a numerical simulation of radiation scattering in a porous media [5]. For porosities higher than those presented in this paper, the optical thickness of the ceramics can probably be lower than the thickness of the single crystal and, as a result, the ceramics emissivity should be lower than the emissivity of the single crystal. 
These explanations enable to understand the behavior observed on Figure 8 between the two ceramics with quasi the same total porosity but different textures. For wavenumbers higher than $1800 \mathrm{~cm}^{-1}$, these two ceramics possessed an emissivity higher than the single crystal. In this range, due to the weak absorption coefficient, the radiation mean path inside the sample was higher than the thickness of the single crystal. Then, the emissivities of the ceramics are higher than those of the single crystal as previously observed. For wavenumbers between 1300 and $1800 \mathrm{~cm}^{-1}$, the emissivity of the $\mathrm{Al}\left(\mathrm{D}^{\prime}\right)-23.2$ ceramic was lower than those of the single crystal. A qualitative comparison of the texture of both ceramics shows that the mean pore size of the $\mathrm{Al}\left(\mathrm{D}^{\prime}\right)-23.2$ ceramic is 40 times as high as the mean pore size of the $\mathrm{Al}(\mathrm{C})$ 20.6 ceramic (Figure 2 and Figure 3). This difference was sufficient to change drastically the nature of the radiation scattering in the $\mathrm{Al}\left(\mathrm{D}^{\prime}\right)-23.2$ ceramic. In this case, the mean size of the pore radius was about $10 \mu \mathrm{m}$, and the radiation scattering follows roughly the optical geometric laws. In this type of radiation scattering, backscattering was very efficient and drive for a one millimeter thick sample to a diffuse reflectivity much more important than the diffuse transmissivity. With these considerations it is concluded that the apparent optical thickness of the sample between 1300 and $1800 \mathrm{~cm}^{-1}$ is lower than those of the corresponding single crystal or in other words, only radiation of a small layer near the surface sample can contribute to the emissivity. In this case, backscattering was more efficient than the radiation absorption. On the contrary, for the CEA samples the mean size of the pore radius was about $0.25 \mu \mathrm{m}$, value that was sufficiently small to prevent scattering to follow optic geometric laws [5]. Furthermore, the ceramic grains are small enough to allow frustrated reflection and then induced less efficient backscattering. For this sample and within this spectral range, absorption coefficient mastered the backscattering behavior and led to the observed result. Then, the spectral radiative properties were completely dependent on the competition between the absorption coefficient (following the wavelength) and the radiative scattering.

\section{Conclusion}

In this paper, we showed the effect of extrinsic parameters such as porosity and texture on the thermal-radiative properties of alumina ceramics. Even if the behaviors observed for these materials are not valid for all ceramics, this rapid presentation pointed out the obligation to take into account these parameters. Besides, this paper emphasizes the different mistakes that 
could be made (and now avoided) in laboratory, industry or in design department without any care. As emissivity in the transparent zone depends on extrinsic parameters, it is not possible to predict the spectral value of emissivity only by the knowledge of intrinsic parameters (refractive index and extinction coefficient) and the thickness of a material. Indeed, as explained before, the modifications in the semitransparent and transparent zones were essentially due to the bulk texture and porosity. In the opaque zone, the increase and the spectral modification of the emissivity were mainly due to the structure of the ceramic surface. These results show for instance the necessity to have the exact characteristics of a ceramic to measure correctly its temperature with an optical pyrometer. In the same way, these textural changes must be taken into account in the input data used for modeling the heat transfer inside processes at high temperature such as a glass making furnace. In a future work, it will be interesting to verify if the critical porosity threshold observed for alumina ceramics is or not highly texture dependent. 
References

1. J.R. Markham, P.R. Solomon, P.E. Best, Rev. Sci. Instrum., 61, 3700 (1990).

2. O. Rozenbaum, D. De Sousa Meneses, S. Chermanne, Y. Auger, P. Echegut, Rev. Sci. Instrum., 70, 4020 (1999).

3. D.De Sousa Meneses, J.F.Brun, P.Echegut, P.Simon, Applied Spectroscopy, 58, 969 (2004).

4. R. Siegel, J.R. Howell, Thermal radiation of heat transfer. Taylor \& Francis, Bristol P.A, 1992.

5. O. Rozenbaum, D. De Sousa Meneses, P. Echegut, P. Levitz, High Temp. High Pressures, 32, 61 (2000).

6. J.G.J. Peelen, Sci. Ceram., 6, 1 (1973).

7. J.G.J. Peelen, R. Metselaar, J. Appl. Phys., 45, 216 (1974).

8. E. Grimm, G.E. Scott, J.D. Sibold, Ceram. Bull., 50, 962 (1971).

9. J.W. Salisbury, L.S. Walter, J. Geophys. Res, 94, 9191 (1989).

10. J.W. Salisbury, A. Wald, Icarus, 96, 121 (1992).

11. W.W. Chen, B. Dunn, J. Am. Ceram. Soc., 76, 2086 (1993).

12. R. Lopes, L.M. Moura., A. Delmas, High Temp. High Press., 31, 213 (1999).

13. D.W. Budworth, Spec. Ceram., 5, 185 (1970).

14. D. De Sousa Meneses, J.F. Brun, B. Rousseau, P. Echegut, J. Phys. Cond. Matter, 18, 5669 (2006).

15. R.J.P. Lyon,. Econ. geol., 60, 717 (1968).

16. G.R. Hunt, R.K. Vincent, J. Geophys. Res., 73, 6039 (1968).

17. J.E. Conel, J. Geophys. Res., 74, 1614 (1969).

18. J.E. Moersch, P.R. Christensen, J. Geophys. Res., 100, 7465 (1995).

19. J.F. Mustard, J.E. Hays, Icarus, 125, 145 (1997).

20. S.K. Anderson, C.G. Ribbing, Phys. Rev. B, 49, 11336 (1994).

21. D.W. Lee, W.D. Kingery, J. Am. Ceram. Soc., 43, 594 (1960).

22. T. Makino, T. Kunitomo, I. Sakai, H. Kinoshita, Heat trans. Jap. Res., 13, 33 (1985).

23. T. Burger J. Kuhn R. Caps, J. Fricke, Appl. Spectrosc., 51, 309 (1997).

24. W.L. Dunn, J. Quant. Spectrosc. Radiant. Transfer, 29, 19 (1983). 
Figures captions

Table 1: textural data for alumina ceramics.

Figure 1 : alumina ceramic Al(C)-3.8 (CEA). Sintering temperature: 1773 K. Porosity: 3.8\%. Figure 2 : alumina ceramic $\mathrm{Al}(\mathrm{C})-20.6$ (CEA). Sintering temperature: $1623 \mathrm{~K}$. Porosity: $20.6 \%$.

Figure 3 : alumina ceramic $\mathrm{Al}\left(\mathrm{D}^{\prime}\right)-23.2$ (Desmarquest). Sintering temperature: $2003 \mathrm{~K}$. Porosity: $23.2 \%$.

Figure 4 : normal spectral emissivities of an alumina single crystal and alumina ceramics for various porosities. (thickness $=1 \mathrm{~mm}, \mathrm{~T}=1350 \mathrm{~K}$ ).

Figure 5 : influence of the porosity in the phonon zone on normal spectral emissivities of alumina ceramics (thickness $=1 \mathrm{~mm}, \mathrm{~T}=1350 \mathrm{~K}$ ). The normal spectral emissivity of an alumina single crystal (thickness $=1 \mathrm{~mm}, \mathrm{~T}=1350 \mathrm{~K}$ ) was given as reference.

Figure 6 : influence of the porosity in the transmission edge of alumina ceramics (thickness $=1$ $\mathrm{mm}, \mathrm{T}=1350 \mathrm{~K}$, from CEA). The normal spectral emissivity of an alumina single crystal (thickness $=1 \mathrm{~mm}, \mathrm{~T}=1350 \mathrm{~K}$ ) was given as reference.

Figure 7 : evolution of the normal spectral emissivity of alumina ceramics (thickness $=1 \mathrm{~mm}$ ) versus porosity: $\mathrm{T}=1350 \mathrm{~K}$

Figure 8 : normal spectral emissivity of alumina ceramics (thickness $=1 \mathrm{~mm}, \mathrm{~T}=1350 \mathrm{~K}$ ) with two different textures. 
Table caption

Table 1: Main characteristics of the ceramics studied.

\begin{tabular}{|c|c|c|c|c|}
\hline Origin & Sample & $\begin{array}{c}\text { Total } \\
\text { porosity } \\
(\%)\end{array}$ & $\begin{array}{l}\text { Average grain } \\
\text { diameter in } \mu \mathrm{m}\end{array}$ & $\begin{array}{c}\text { Sintering } \\
\text { temperature } \\
(\mathrm{K})\end{array}$ \\
\hline \multirow{3}{*}{ DESMARQUEST } & $\mathrm{Al}(\mathrm{D})-0.6$ & $0.6 \pm 0.1$ & 1 to 6 & 1883 \\
\hline & $\mathrm{Al}(\mathrm{D})-3.5$ & $3.5 \pm 0.2$ & 0.5 to 1 & 1623 \\
\hline & $\mathrm{Al}\left(\mathrm{D}^{\prime}\right)-23.2$ & $23.2 \pm 0.4$ & 5 to 50 & 2003 \\
\hline \multirow{9}{*}{ CEA } & $\mathrm{Al}(\mathrm{C})-3.8$ & $3.8 \pm 0.1$ & 0.5 to 3 & 1773 \\
\hline & $\mathrm{Al}(\mathrm{C})-4.1$ & $4.1 \pm 0.1$ & 0.5 to 3 & 1773 \\
\hline & $\mathrm{Al}(\mathrm{C})-4.3$ & $4.3 \pm 0.4$ & 0.5 to 3 & 1773 \\
\hline & $\mathrm{Al}(\mathrm{C})-9.1$ & $9.1 \pm 0.2$ & 0.5 to 1.5 & 1693 \\
\hline & $\mathrm{Al}(\mathrm{C})-9.6$ & $9.6 \pm 0.4$ & 0.5 to 1.5 & 1673 \\
\hline & $\mathrm{Al}(\mathrm{C})-10.3$ & $10.3 \pm 0.4$ & 0.5 to 1.5 & 1673 \\
\hline & $\mathrm{Al}(\mathrm{C})-20.6$ & $20.6 \pm 0.1$ & 0.5 to 1 & 1623 \\
\hline & $\mathrm{Al}(\mathrm{C})-28.6$ & $28.6 \pm .0 .1$ & 0.5 to 1 & 1573 \\
\hline & $\mathrm{Al}(\mathrm{C})-29.2$ & $29.2 \pm 0.2$ & 0.5 to 1 & 1573 \\
\hline
\end{tabular}




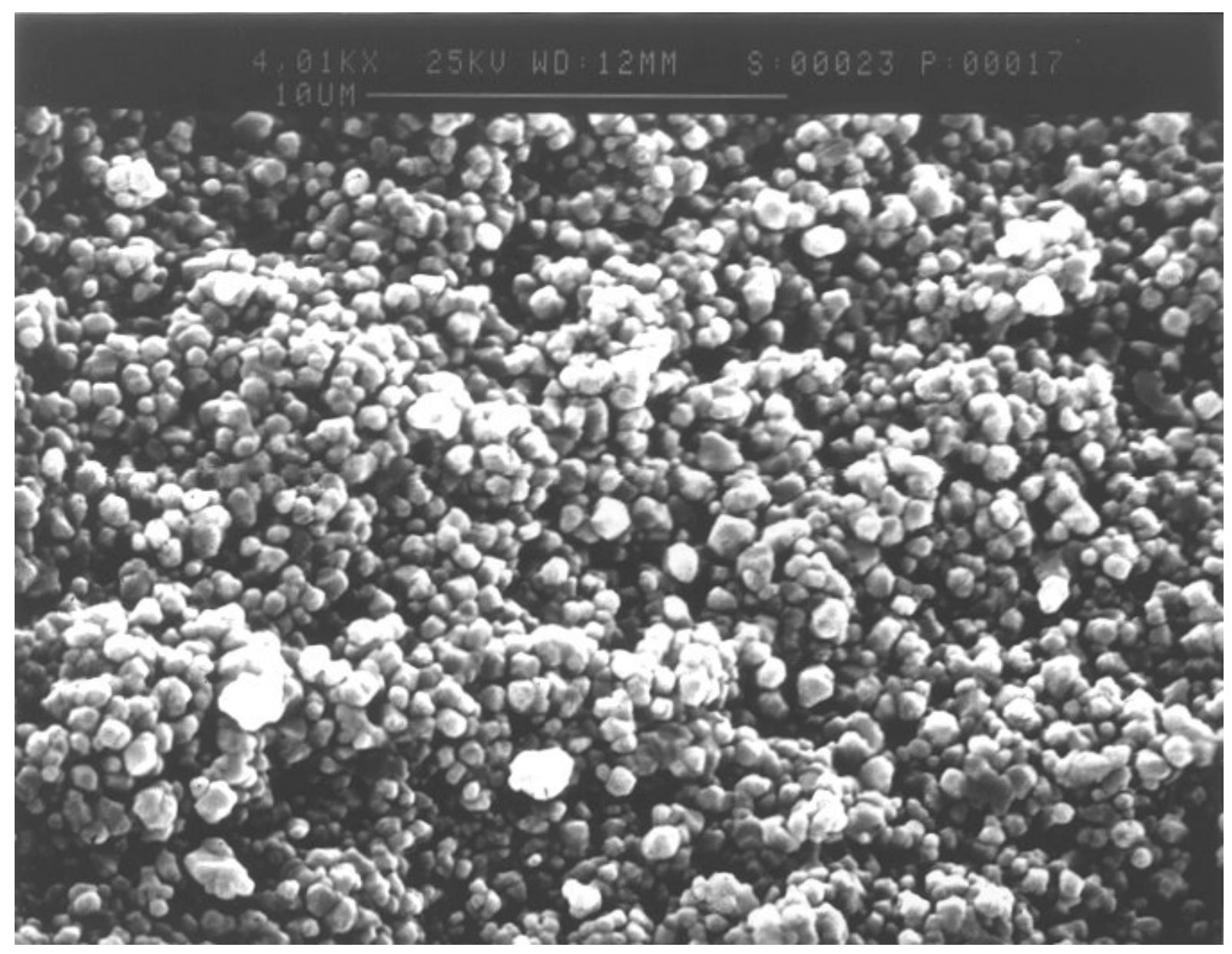




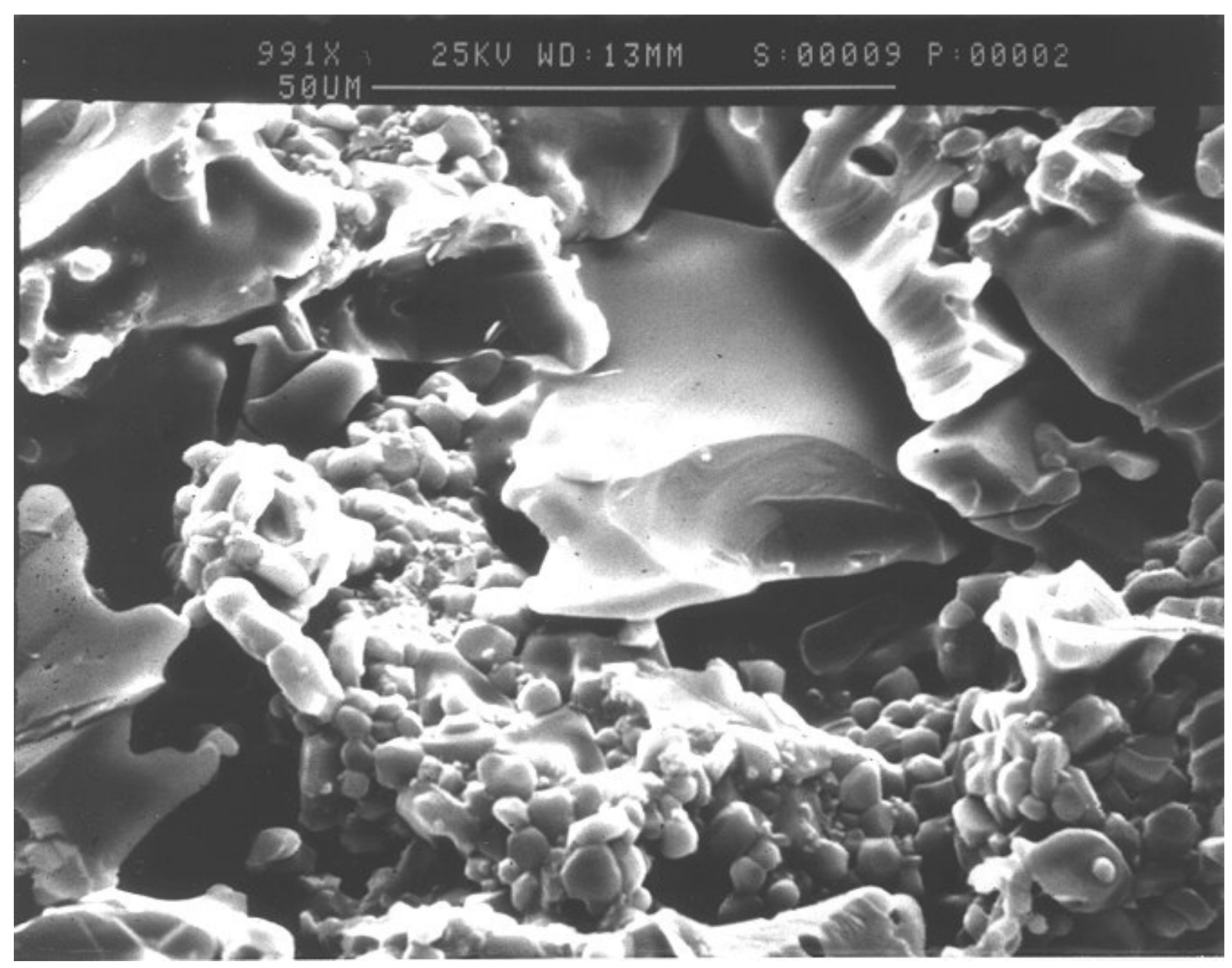



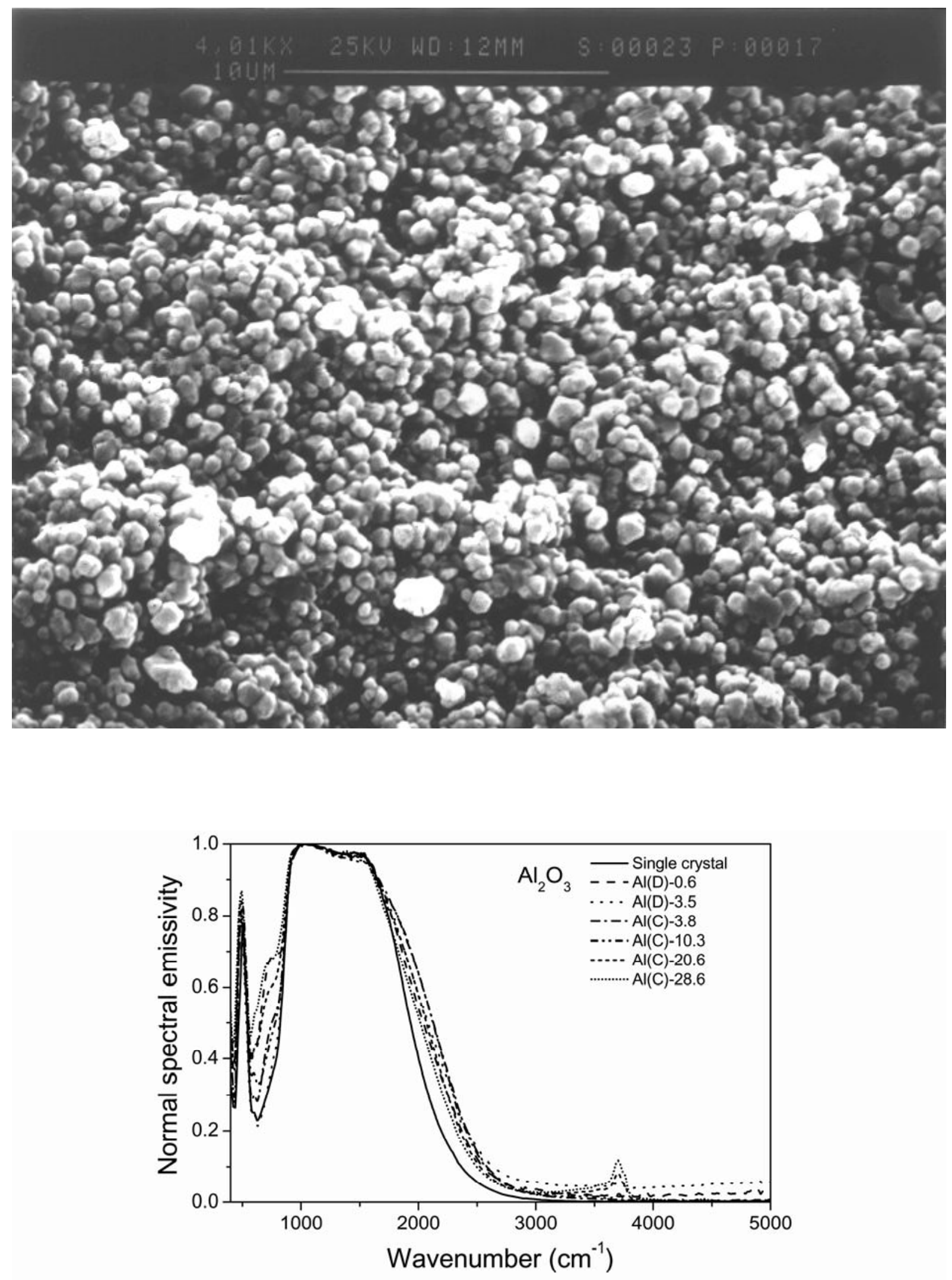


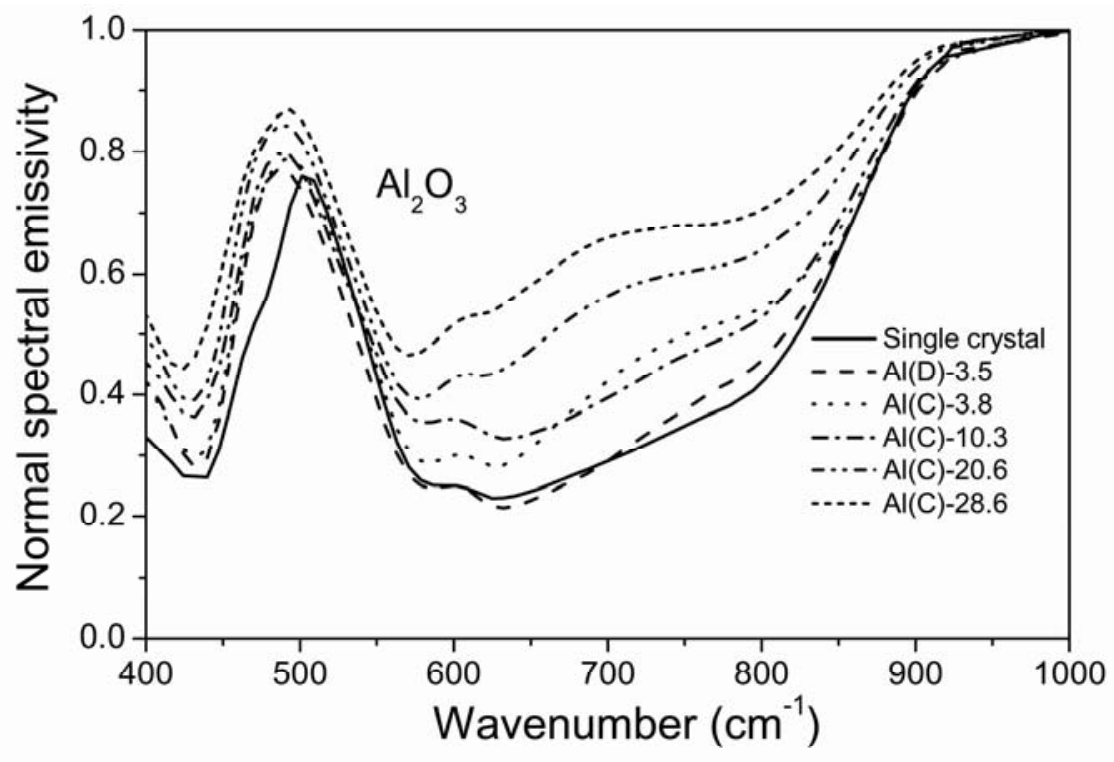



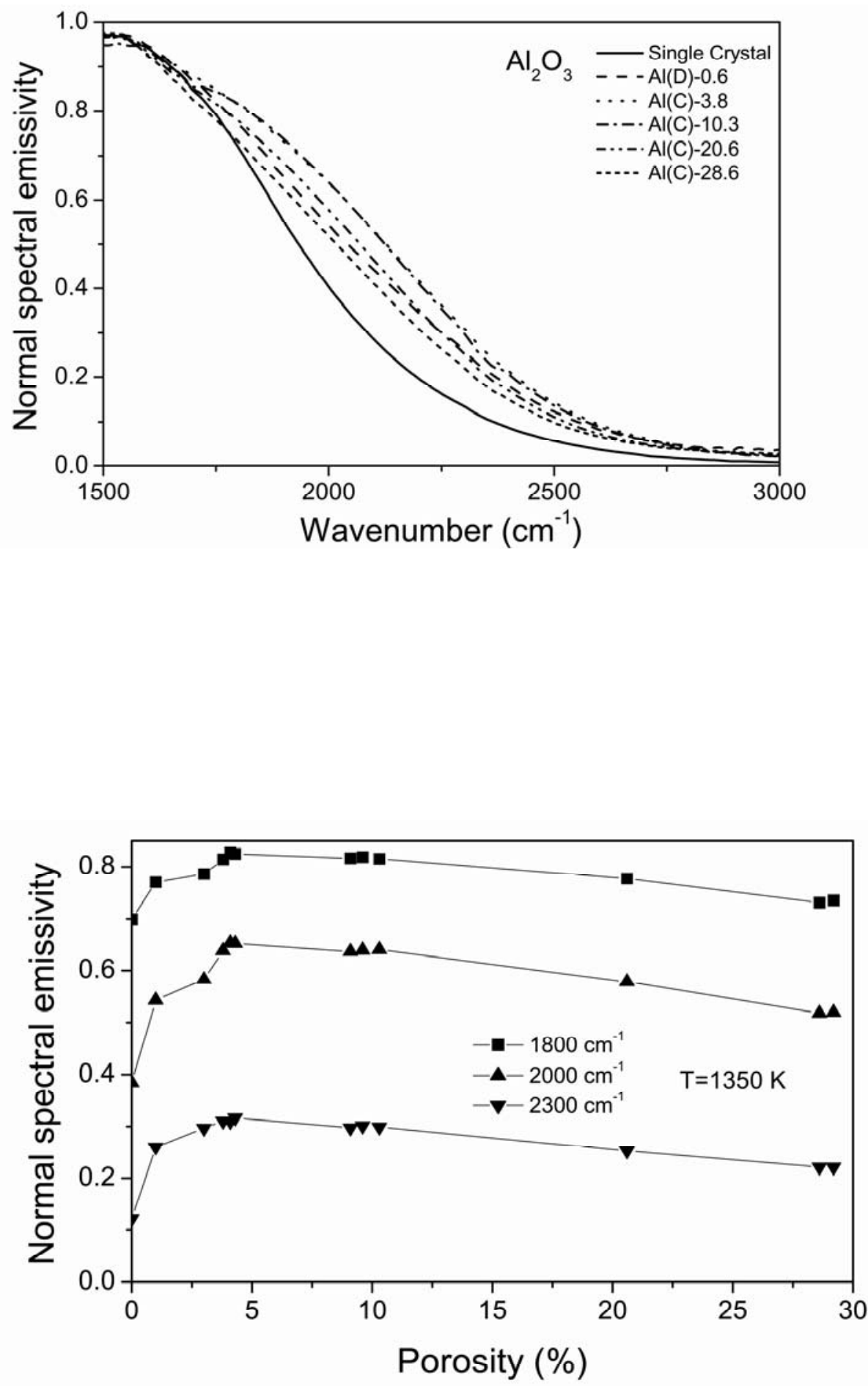


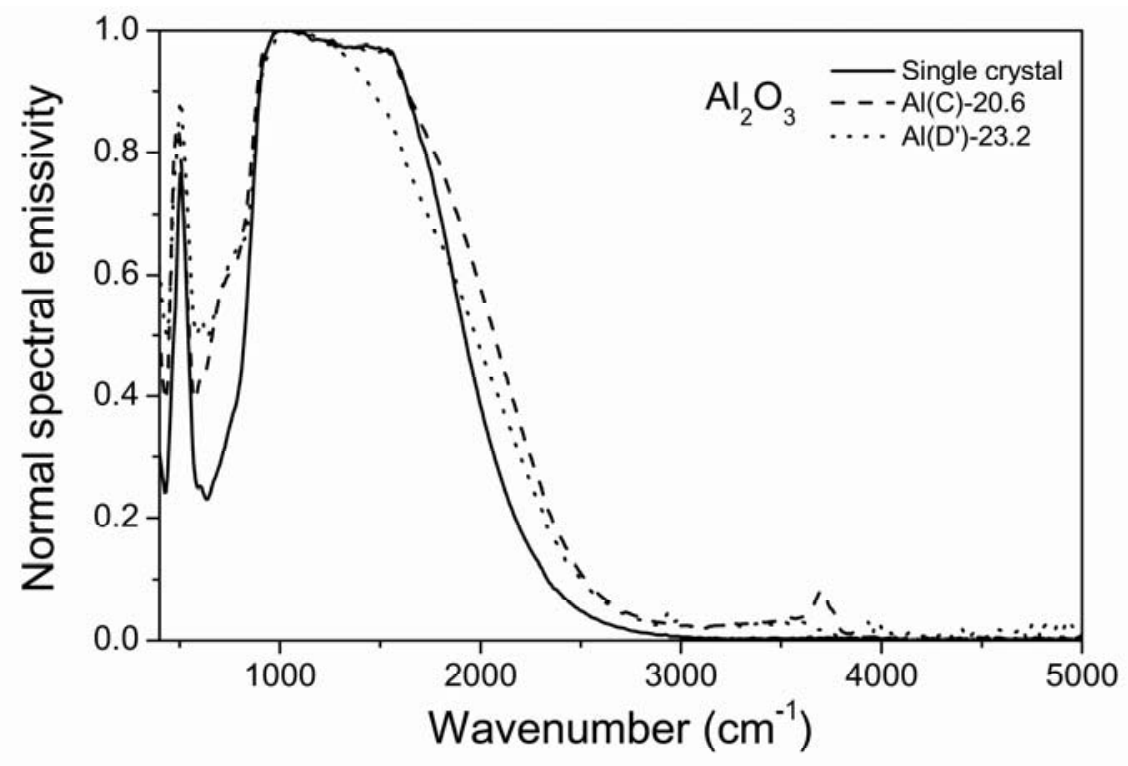

